\title{
Effects of an Ankle Foot Orthosis with Ankle Angles on Balance Performance in Healthy Adults
}

\author{
Chung Sun Kim', Sang Young Park ${ }^{2}$ \\ ${ }^{1}$ Department of Physical Therapy, Daegu University, Gyeongsan, 712-714 \\ ${ }^{2}$ Department of Rehabilitation Science, Daegu University, Gyeongsan, 712-714
}

\begin{abstract}
This study was designed to investigate the effects of an ankle foot orthosis(AFO) with variable ankle joint angles on balance performance in healthy adults. Eighteen healthy adults were recruited in this repeated measures design with subjects as their own controls. An AFO with four kinds of ankle joint angles(-5, 0, 5, and 10 degree) were used and balance performance was measured during single limb standing. Three trials were obtained and then averaged for data analysis. Foot pressure was measured using an F-scan system and muscle activity was measured using an MP150 system. There were significant differences in balance performance with ankle joint angles. An AFO with -5 degrees was associated with significant increases in postural sway(anterior-posterior), and in muscle activity for the medial gastrocnemius and tibialis anterior compared with other degrees of angle. Findings of this study show that angles of an AFO are related to balance performance and a joint angle of 10 degree is effective for promoting joint stability and postural control. This information can be used by clinicians to prescribe AFOs.
\end{abstract}

Keywords: Ankle foot orthosis, Ankle angle, Balance

\section{1. 서 론}

균형이나 자세의 안정성은 정적인 자세를 유지하거나 원 하는 동작을 수행하기 위해서 지지면 내에 신체 중심을 유 지하는 것을 의미하게 된다. 균형을 유지, 조절하기 위해서 는 고유수용성 감각, 시각, 전정 감각 등의 상호 작용이 적 절하게 조화를 이루어야 한다(서삼기 등, 2009; Chen et al., 2008). 이러한 요소의 이상이나 중추신경계의 손상, 근골격계의 손상에 의해서 균형 능력과 일상생활에 장애를 일으키게 된다. 특히 신체의 작은 움직임을 주로 조절하는 발목 관절의 근력 약화나 고유수용성 감각의 문제로 인하 여 자세 조절의 어려움이 많이 나타나게 된다(Wang et al., 2005).

발목 관절에 문제가 나타날 수 있는 질환은 뇌졸중 등의
중추신경계 손상과 발목으로 내려가는 말초신경 손상 등에 의해서 발생한다. 뇌졸중은 전반적으로 비대칭적인 체중지지 자세와 족하수, 첨족, 전반슬, 감각 장애 등으로 인하여 낙상 의 위험이 높아지고 자세 조절의 안정성을 유지하기 어려워 진다. 뇌졸중 환자의 균형 문제는 외부의 외력으로부터 안 정성을 유지하는 것이나 움직임을 시작하는 것에 어려움이 나타나며, 양 발 지지에서 손상측으로 관상면에서의 체중 이 동과 시상면에서 전후의 신체 동요가 크게 나타나게 된다 (Wang et al., 2005). 이러한 뇌졸중 환자의 균형과 보행의 문제에 논란이 없는 것은 아니지만 단하지 보조기가 이용 되고 있다(Churchill et al., 2003; Fatone et al., 2009; Pohl and Mehrholz, 2006; Wang et al., 2005).

단하지 보조기는 일반적으로 발목 관절의 안정성을 제공 하고, 보행 속도의 증가와 보행 중의 에너지 감소를 목적으 로 처방되며, 불충분한 배측 굴곡과 거골하 관절의 내외측

Corresponding Author: Sang Young Park. Department of Rehabilitation Science, Daegu University, Gyeongsan, $712-714$.

Mobile: 010-4509-7425, E-mail: acaprio@hanmail.net

Copyright@2011 by Ergonomics Society of Korea(pISSN:1229-1684 eISSN:2093-8462). All right reserved. 
불안정성을 보상해 주어 균형 능력을 증가시키는 역할을 하게 된다(송창호와 이승원, 2004; Esquenazi et al., 2009; Fatone et al., 2009; Nolan et al., 2009). 또한 단하지 보 조기의 사용은 신체의 중심을 내측으로 이동시킬 수 있고 손상측 발쪽으로 체중 이동이 쉽게 되도록 하며 신체의 비 대칭성을 감소시킨다. 그러나 단하지 보조기는 신체의 균형 을 유지에 작용하는 발의 저측 굴곡의 움직임을 제한하게 되며, 초기의 뇌졸중 환자에는 정적, 동적 균형에 효과적이 나 만성기의 환자에서는 효과가 약하게 나타난다(Wang et al., 2005).

여러 연구에서 단하지 보조기의 착용 유무에 따라 보행 에 미치는 효과에 관련되어 논의되었고(Esquenazi et al., 2009; Fatone et al., 2009; Nolan et al., 2009), 단하지 보 조기의 형태에 따른 자세 안정성이나 균형에 미치는 영향에 관련된 연구들이 있었으나(Chen et al., 2008; Chen et al., 1999; Wang et al., 2005), 실제 임상에서 제작에 이용되는 단하지 보조기의 발목 관절 각도에 관련된 연구는 거의 없 으며 균형과 관련된 연구가 미흡한 실정이다. 따라서 본 연 구의 목적은 정상인에서 임상에 사용되는 단하지 보조기의 발목 관절 각도가 서기 자세에서 균형에 미치는 영향을 확 인하여 배측 굴곡근이 약한 환자나 발의 불안정성이 있는 환자의 단하지 보조기 처방에 기초자료를 제공하고자 한다.

\section{2. 연구 방법}

\section{1 연구대상}

본 연구에는 신경학적인 병력이 없고, 근골격계의 질환 병력이 없는 정상 성인 18 명을 대상으로 선정하였다. 모든 대상자는 실험에 참가하기 전 연구 목적과 방법에 대하여 충분한 설명을 듣고, 이에 자발적 동의를 한 후, 연구에 참여 하였다. 연구대상자의 일반적인 특성은 표 1 과 같고, 발 사 이즈는 265 270mm로 제한하였다.

표 1. 연구대상자의 일반적인 특성

\begin{tabular}{c|c}
\hline & 연구대상자 $(18)$ \\
\hline 나이 & $26.33 \pm 0.47$ \\
\hline 키 $(\mathrm{cm})$ & $174.00 \pm 0.94$ \\
\hline 몸무게 $(\mathrm{kg})$ & $70.06 \pm 1.57$ \\
\hline 발길이 $(\mathrm{mm})$ & $268.33 \pm 0.57$ \\
\hline
\end{tabular}

\section{2 실험방법}

\subsection{1 측정도구}

근활성도

하지의 근활성도를 이용한 측정값을 얻기 위해 MP150 (Biopac System, USA)을 이용하며, 전극에는 근 섬유의 활동 전위가 발생되는 것을 근육 위에 있는 피부로부터 유도 하기 위하여 $\mathrm{Ag}-\mathrm{Ag} / \mathrm{Cl}$ (Biopac, diameter $2 \mathrm{~cm}$ ) 표면 전극 을 사용하여 부착하였다. 측정하기 전 피부 저항을 최소화하 기 위하여 전극 부착 부위를 면도한 후 알코올로 닦아내고, 전극 부착 부위가 완전히 마른 후에 전해질 겔이 도포된 두 개의 활성 전극과 접지 전극을 피부에 부착한다. 각 근육의 표면 전극의 부착 부위는 근 섬유 방향과 평행하게 도수근력 검사를 통하여 근육이 가장 활성화되는 부분인 근복의 중간 부위를 찾아 부착하고, 부착 부위는 모두 4 군데로 전경골근, 내측 비복근, 대퇴직근, 대퇴이두근에 부착하였다(그림 1).

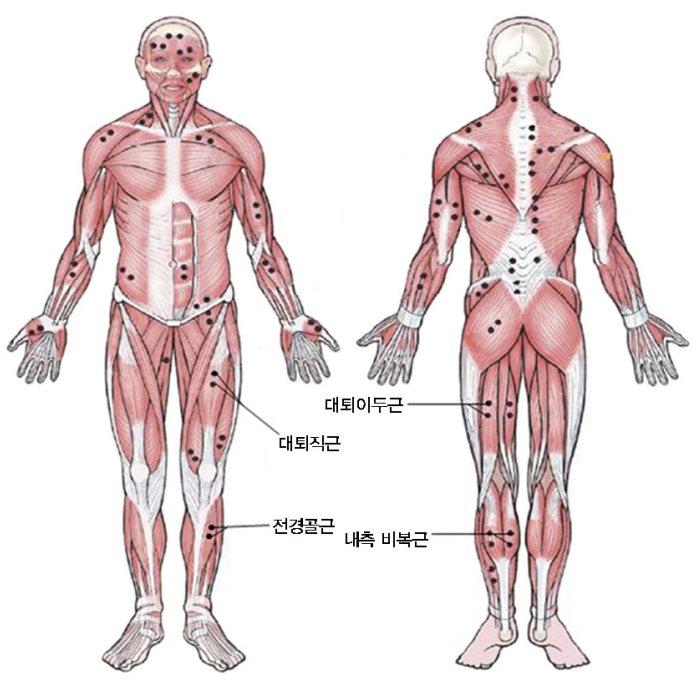

그림 1. 표면근전도의 부착 부위

근전도 신호는 생체 신호에 대한 아날로그 신호를 디지털 화 하여 $1,000 \mathrm{~Hz}$ 의 신호획득률(sampling rate)로 수집한 후, 완파정류(full-wave rectification)로 처리를 하고, 실 효치값(root mean square: RMS)을 컴퓨터 파일로 저장 하여 자료 처리에 이용한다. 자료 처리는 Acqknowledge 3.8.1 (Biopac System, USA) 소프트웨어를 사용하여 30 $500 \mathrm{~Hz}$ 에서 구간 필터링을 하고 잡음제거를 위해 $60 \mathrm{~Hz}$ 로 notch 필터링하여 기타 처리를 한다.

족저압

균형을 평가하기 위한 한 발 서기에서 족저압을 측정하기 
위하여 Matrix 형태의 저항식 압력 센서인 F-scan system (Tekscan, USA)을 이용하였다. 센서는 단하지 보조기의 크기에 맞게 잘라서 단하지 보조기 내에 넣어 족저압을 측 정할 수 있는 삽입형으로 960개의 압력 감지점이 격자 형식 으로 분포되어 있는 얆은 필름의 형태이다. 각각의 압력 감 지점으로부터 기록된 압력은 변환 장치를 거쳐 컴퓨터로 전송되어 Teckscan의 상용프로그램을 이용하여 60frame/ sec로 자료를 수집하였고, Pressure measurement system 을 이용하여 발바닥 영역을 구분하여 족저압을 분석하였다.

한 발 서기 자세에서 족저 압력을 측정하기 위해서 해부 학적인 관점에서 크게 전족부, 중족부, 후족부로 나누어서 각 족저 영역의 최대값을 수집하였다. 또한 압력중심 이동 경로의 값을 전후와 좌우 거리를 각각 측정하였다.

\section{실험절차}

본 연구에 이용된 단하지 보조기는 발목의 관절 각도를 조절할 수 있도록 제작된 것으로 족관절의 중립 위치(0도), 5 도 배측 굴곡 위치(5도), 10도 배측 굴곡 위치(10도), 5도 저측 굴곡 위치 $(-5$ 도)로 시행하였으며, 학습에 의한 효과 를 상쇄시키기 위해서 발목 관절 각도의 순서를 다르게 하 여 측정하였다(그림 2).

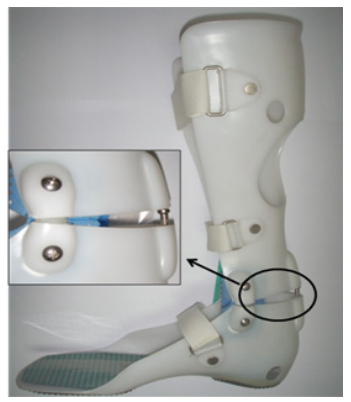

그림 2. 제작된 단하지 보조기

정확한 족저 압력을 측정하기 위해 측정 전 대상자들에게 자세를 설명하고, 실험과 같은 동작을 연습할 수 있는 기회 를 1 분 동안 제공하였다. 한 발 서기는 단하지 보조기를 착 용한 오른쪽 발로 지지면에 지지하고 왼발은 무릎을 굽혀서 지면에 닿지 않게 하였고, 팔은 흔들지 않도록 양 손을 대 상자의 가슴으로 가져와 팔짱을 끼도록 하였다. 눈은 $3 \mathrm{~m}$ 앞에 위치한 둥근 점을 주시하면서 발을 떼고 팔짱을 낀 상 태에서 측정을 시작하여 족저압과 근활성도를 10 초씩, 3 회 측정하였다. 시작 후 1 초와 끝나기 전 1 초를 제외한 8 초를 3 회 평균을 이용하여 분석하였으며 각 측정 사이에는 1 분 간 휴식, 발목 관절 각도를 조절할 때는 5 분 간의 충분한 휴식을 취하게 하였다.
근육 활성도는 족저 압력을 측정하는 동안 동시에 측정하 였으며, 한 발 서기를 하는 동안 전경골근, 내측 비복근, 대 퇴직근, 대퇴이두근에서 측정하였고, 측정된 근육의 근전도 신호량을 표준화 하기 위해서 근전도 신호의 실질적인 출 력값에 가까운 값을 제공하는 RMS (root mean square) 값 을 취하여 수의적 최대 등척성근수축(maximal voluntary isometric contraction, MVIC) 값의 적분근전도값(integral electromyogram, IEMG)으로 나누어 백분율로 환산한 값 인 \%MVC 값을 사용하였다.

\section{3 자료분석}

수집된 자료는 평균 및 표준 오차로 제시하였고, SPSS 15.0 을 이용하여 통계 처리하였다. 단하지 보조기의 족관절 발목 관절 각도에 따른 족저압과 근활성도를 비교하기 위해 반복측정 (repeated measure ANOVA)을 이용하였다. 모 든 통계학적 유의수준은 $\alpha=0.05$ 로 설정하였다.

\section{3. 연구 결과}

\section{1 발목 관절 각도에 따른 압력중심의 이동과 영역별 족저 최고 압력값 비교}

발목 관절 각도에 따른 압력중심의 이동에서 전후 방향의 이동은 단하지 보조기의 $10,-5$ 도와 다른 각도에서 유의한 차이가 나타났으나 $(p<0.05)$, 내외 방향의 이동은 각도에 따 라 유의한 차이가 나타나지 않았다 $(p>0.05)$ (표 2). 발바 닥의 영역별 최고 압력값에서 전족부, 중족부, 후족부 모두 각도에 따라 유의한 차이를 보였다 $(p<0.05$ ) (표 2). 전족부 에서는 발목 관절 각도가 증가함에 따라서 감소하는 경향이 나타났고, 중족부와 후족부에서는 각도의 증가에 따라 증가 하는 경향이 나타났다. 또한 사후 검정 결과 전족부와 중족 부에서는 -5 도에서만 차이를 보였고, 후족부에서는 각도에 따라서 유의한 차이가 나타났다 $(p<0.05)$ (표 2).

\section{2 발목 관절 각도에 따른 하지의 근활성도 비교}

단하지 보조기의 발목 관절 각도에 따른 근활성도를 비 교한 결과, 비복근과 전경골근에서 유의한 차이를 보였으 나 $(p<0.05)$, 대퇴직근과 대퇴이두근에서는 차이가 없었다 ( $p>0.05)$ (표 3$)$. 사후 검정 결과 내측 비복근은 -5 도와 10 도의 값과 맨발, 0 도, 5 도의 값에서 유의한 차이가 나타 났고 $(p<0.05)$, 전경골근은 -5 도의 값과 다른 각도의 값에 서 유의한 차이가 나타났으며, 5 도와 맨발에서도 차이가 나 
표 2. 발목 관절 각도에 따른 압력중심 이동과 족저압 비교

\begin{tabular}{c|c|c|c|c|c|c|c}
\hline \multicolumn{2}{c|}{} & $-5^{\circ}$ & $0^{\circ}$ & $5^{\circ}$ & $10^{\circ}$ & $\mathrm{F}$ & $p$ \\
\hline \multirow{2}{*}{$\begin{array}{c}\text { 압력중심 } \\
(\mathrm{cm})\end{array}$} & 전후 & $7.90 \pm 0.21^{\mathrm{a}}$ & $6.62 \pm 0.31^{\mathrm{b}}$ & $6.82 \pm 0.29^{\mathrm{b}}$ & $5.99 \pm 0.28^{\mathrm{c}}$ & 14.73 & $0.00^{*}$ \\
\cline { 2 - 9 } & 내외 & $3.03 \pm 0.10$ & $2.97 \pm 0.12$ & $3.05 \pm 0.14$ & $2.96 \pm 0.15$ & 0.17 & 0.91 \\
\hline \multirow{3}{*}{$\begin{array}{c}\text { 족저압 } \\
(\mathrm{kPa})\end{array}$} & 전족부 & $850.11 \pm 49.13^{\mathrm{a}}$ & $635.94 \pm 32.20^{\mathrm{b}}$ & $637.78 \pm 32.85^{\mathrm{b}}$ & $617.78 \pm 44.27^{\mathrm{b}}$ & 10.80 & $0.00^{*}$ \\
\cline { 2 - 9 } & 중족부 & $281.06 \pm 19.38^{\mathrm{a}}$ & $336.67 \pm 16.42^{\mathrm{b}}$ & $333.72 \pm 20.11^{\mathrm{b}}$ & $349.06 \pm 29.49^{\mathrm{b}}$ & 3.65 & $0.02^{*}$ \\
\cline { 2 - 10 } & 후족부 & $603.11 \pm 54.20^{\mathrm{a}}$ & $682.17 \pm 41.78^{\mathrm{b}}$ & $768.11 \pm 50.27^{\mathrm{c}}$ & $829.22 \pm 31.94^{\mathrm{d}}$ & 7.36 & $0.00^{*}$ \\
\hline
\end{tabular}

${ }^{*} p<0.05$

$\mathrm{a}, \mathrm{b}, \mathrm{c}$ : 다른 문자는 각 관절 각도에서 유의한 차이를 의미함 $(p<0.05)$

표 3. 발목 관절 각도에 따른 하지의 근활성도 비교

\begin{tabular}{c|c|c|c|c|c|c|c}
\hline 근육 $(\% \mathrm{MVC})$ & $-5^{\circ}$ & $0^{\circ}$ & $5^{\circ}$ & $10^{\circ}$ & 맨발 & $\mathrm{F}$ & $p$ \\
\hline 내측 비복근 & $43.53 \pm 3.28^{\mathrm{a}}$ & $35.36 \pm 4.89^{\mathrm{b}}$ & $36.38 \pm 4.85^{\mathrm{b}}$ & $43.91 \pm 4.71^{\mathrm{a}}$ & $34.13 \pm 4.30^{\mathrm{b}}$ & 3.43 & $0.01^{*}$ \\
\hline 전경골근 & $11.99 \pm 1.05^{\mathrm{a}}$ & $8.79 \pm 0.90^{\mathrm{c}}$ & $9.26 \pm 1.57^{\mathrm{b}}$ & $8.80 \pm 1.53^{\mathrm{c}}$ & $6.66 \pm 0.93^{\mathrm{d}}$ & 4.47 & $0.00^{*}$ \\
\hline 대퇴직근 & $7.19 \pm 1.39$ & $7.65 \pm 1.23$ & $7.12 \pm 0.99$ & $7.76 \pm 1.12$ & $6.62 \pm 1.20$ & 0.47 & 0.76 \\
\hline 대퇴이두근 & $8.31 \pm 1.33$ & $7.90 \pm 1.27$ & $6.93 \pm 1.21$ & $7.77 \pm 1.40$ & $7.37 \pm 1.36$ & 1.15 & 0.34 \\
\hline
\end{tabular}

${ }^{*} p<.05$

$\mathrm{a}, \mathrm{b}, \mathrm{c}, \mathrm{d}:$ 다른 문자는 각 관절 각도에서 유의한 차이를 의미함 $(p<0.05)$

타났다 $(p<0.05)$.

\section{4. 고 찰}

뇌졸중 환자의 치료와 평가에 있어서 보행분석은 독립적 인 생활이나 기능적인 상태를 확인하는 것에서 효과적이다. 또한 균형의 평가와 치료는 뇌졸중 환자의 치료에 있어 낙 상의 위험 등을 감소시키는 중요한 역할을 한다(Nolan et al., 2009). 자세의 조절은 운동과 감각의 복합적인 절차에 의해서 이루어지게 되고 이상적인 자세 조절은 기저면 내에 신체 중심을 유지하는 것이라고 할 수 있으며 유지방법으로 작은 동요에 적용되는 발목 관절 전략을 가장 먼저 이용하게 되고 발의 근력이나 감각의 문제가 있는 경우에 균형을 유 지하는 것이 어려워진다. 발목 관절 전략은 발목의 적절한 가동 범위와 근력이 필요하게 되며, 단하지 보조기는 발목 관절의 안정성과 적절한 체중 부하를 제공해 주는 동시에 발목 관절의 움직임을 제한하게 되어 동요가 커지게 되면 엉덩 관절 전략을 이용하게 된다(Chen et al., 2008; Wang et al., 2005). 본 연구에서는 뇌졸중 환자에게 주로 처방이 되는 단하지 보조기를 이용하여 발목 관절의 관절 각도에 따라 한 발 서기 시의 균형 능력에 미치는 영향을 알아보기 위하여 발목 관절의 관절 각도를 조절할 수 있도록 제작된 단하지 보조기에 족저압 insole을 삽입하여 족저압의 분포
와 근활성도를 알아보았다.

본 연구의 결과 압력중심의 이동은 다른 각도와 비교해서 -5 도에서 전후의 동요와 발목 관절 주위의 근활성도가 크 게 나타났으며 내외측의 동요에는 유의한 차이가 없었다. 이는 발목의 각도에 따라 전후의 움직임이 커졌을 뿐만 아 니라 근육의 활성도가 높아졌음에도 불구하고 자세 조절을 하는 것에 문제가 있는 것으로 나타났고, 단하지 보조기의 목적인 내외측의 안정성은 전경골근, 장비골근, 단비골근 등 의 발목의 내반과 외반에 관여하는 근육의 역할을 보조기가 대신하여 발목의 안정성을 제공하였기 때문에 내외측의 동 요가 차이가 나지 않는 것으로 보였다. 박준민 등(1998)은 정상 성인의 보행 양상에서 -5 도 단하지 보조기의 발목 관 절 운동 범위의 제한이 적어 운동성이 크게 나타났고 무릎 의 과신전을 일으킬 수 있으며 5도 단하지 보조기는 무릎 의 굴곡으로 인하여 대퇴사두근의 과부하로 인하여 무를 관 절의 과굴곡이나 과신전의 상태에 따라 처방에 주의해야 한 다고 하였다. 단하지 보조기의 발목 관절 각도가 10 도에서 전후의 압력중심의 이동이 유의하게 감소되는 것은 무릎의 관절 각도가 약간 굴곡되어 신체 중심의 변화에 의한 발목 전후의 근육의 활성도가 높아지면서 발목의 전후 안정성이 증가되었기 때문이다.

족저압의 최고값은 발목 관절의 각도에 따라서 전족부에 서는 감소하는 경향이 나타났고, 중족부와 후족부에서는 증 가하는 경향이 나타났다. 발목의 각도에 따라 서 있는 자세 에서 발목이 저측 굴곡이 되어 있을 때에는 발의 앞쪽으로 
체중 분포가 나타나고, 배측 굴곡이 되었을 때는 체중이 뒤 쪽으로 분포하는 것을 알 수 있다. 이런 자세의 변화에 따 라 발목을 조절하는 저측 굴곡근과 배측 굴곡근의 근활성도 가 -5 도에서 크게 나타났으며, 각도가 크지 않아 무릎 관 절의 조절에는 크게 영향을 미치지 않는 것으로 나타났다. 이는 일반적으로 구두를 신었을 때 구두의 굽의 높이에 따 라서 발목 주위의 근활성도의 변화와 같은 양상으로 나타났 다(이명희 등, 2009).

Chen 등(2008)은 전방 단하지 보조기 (anterior ankle foot orthosis)를 이용하여 뇌졸중 환자에게 여섯 가지의 환경의 변화 상황에서 균형을 유지하는 것을 비교해 본 결 과 단하지 보조기의 유무에 따라 외측으로 체중의 이동과 손상측의 체중 지지의 증가를 통하여 동적인 안정성에 도움 이 되는 것으로 나타났다. Wang 등(2005)은 단하지 보조 기에 의한 자세 조절의 역할을 뇌졸중 환자의 발병 기간에 따라 분류하여 알아본 결과 초기의 발목의 안정성을 제공 하는 것에는 효과가 크게 나타났으나 만성기 환자에게서는 이미 정렬의 변화, 근육의 단축 등 구조적인 변화가 나타났 으므로 그 효과가 미미한 것으로 나타났다. 또한 Baier와 Hopf(1998)는 발목의 염좌로 인한 불안정성이 있는 젊은 대상자에게 고정 또는 유연한 단하지 보조기를 적용한 결과 내외측의 신체 동요 속도의 감소가 나타났으며 이는 발목의 내외측의 고유수용성 감각의 증가 때문이라고 하였다. 본 연구의 결과에서도 이전 연구와 비슷한 결과를 보였고 발 목의 관절 각도가 자세 조절에 영향을 미치는 것으로 생각 된다.

따라서 본 연구에서는 정상인을 대상으로 연구가 진행되 어 제한점이 있었지만 발목 관절의 관절 각도가 균형에 미 치는 영향을 알 수 있었고, 단하지 보조기를 처방하게 될 때 정상적인 근활성도나 중심 압력의 이동을 확인한 결과 10 도 정도가 적절한 것으로 생각되며, 실제로 발목 관절이 조절 되지 않는 환자를 대상으로 하는 연구가 좀더 이루어져야 할 것으로 생각된다.

\section{5. 결 론}

본 연구에서는 정상 성인을 대상으로 임상에 사용되는 단하지 보조기의 발목 관절 각도가 서기 자세에서 균형에 미치는 영향을 확인한 결과 발목 관절의 각도에 따라 자세 조절이나 근활성도에서 차이가 나타나는 것을 확인하였다. 발목의 안정성과 자세 조절을 위해 10 도 정도의 단하지 보 조기의 처방이 효과적일 것으로 생각되며, 뇌졸중 환자나 발 목 관절의 조절이 되지 않는 환자를 대상으로 연구가 진행
되어야 할 것으로 생각된다.

\section{Acknowledgements}

본 논문은 2008학년도 대구대학교 학술연구비지원에 의 한 논문임.

\section{References}

박준민, 최경효, 전민호, 단하지 보조기의 족관절 각도에 따른 보행 양상의 변화, 대한재활의학회지, 22(5), 1998.

서삼기, 김수현, 김태열, 정상인의 자세와 시각 교란에 따른 정적 균형 능력의 변화, 대한물리치료학회지, 21(4), 51-56, 2009.

송창호, 이승원, 발보조기가 자세 동요에 미치는 효과, 대한물리치 료학회지, 16(2), 229-236, 2004.

이명희, 장종성, 이상열, 주정렬, 배성수, 젊은 여성에서 높은 굽 신발의 착용기간에 따른 정적 균형과 다리 근활성도 분석, 대한물리의학회지, 4(1), 43-48, 2009.

Baier, M. and Hopf, T., Ankle orthoses effect on single-limb standing balance in athletes with functional ankle instability, Arch Phys Med Rehabil, 79(8), 939-944, 1998.

Chen, C. K., Hong, W. H., Chu, N. K., Lau, Y. C., Lew, H. L. and Tang, S. F., Effects of an anterior ankle-foot orthosis on postural stability in stroke patients with hemiplegia, Am J Phys Med Rehabil, 87(10), 815-820, 2008.

Chen, C. L., Yeung, K. T., Wang, C. H., Chu, H. T. and Yeh, C. Y., Anterior ankle-foot orthosis effects on postural stability in hemiplegic patients, Arch Phys Med Rehabil, 80(12), 1587-1592, 1999.

Churchill, A. J., Halligan, P. W. and Wade, D. T., Relative contribution of footwear to the efficacy of ankle-foot orthoses, Clin Rehabil, 17(5), 553-557, 2003.

Esquenazi, A., Ofluoglu, D., Hirai, B. and Kim, S., The effect of an ankle-foot orthosis on temporal spatial parameters and asymmetry of gait in hemiparetic patients, $P M R, 1(11), 1014-1018,2009$.

Fatone, S., Gard, S. A. and Malas, B. S., Effect of ankle-foot orthosis alignment and foot-plate length on the gait of adults with poststroke hemiplegia, Arch Phys Med Rehabil, 90(5), 810-818, 2009.

Nolan, K. J., Savalia, K. K., Lequerica, A. H. and Elovic, E. P., Objective assessment of functional ambulation in adults with hemiplegia using ankle foot orthotics after stroke, $P M R, 1(6), 524-529,2009$.

Pohl, M. and Mehrholz, J., Immediate effects of an individually designed functional ankle-foot orthosis on stance and gait in hemiparetic patients, Clin Rehabil, 20(4), 324-330, 2006.

Wang, R. Y., Yen, L., Lee, C. C., Lin, P. Y., Wang, M. F. and Yang, Y. R., Effects of an ankle-foot orthosis on balance performance in patients with hemiparesis of different durations, Clin Rehabil, 19(1), 37-44, 2005. 


\section{Author listings}

\section{Chung Sun Kim: chskim@daegu.ac.kr}

Highest degree: $\mathrm{PhD}$, Department of Special Education, Daegu University Position title: Professor, Department of Physical Therapy, Daegu University Areas of interest: Neurological Physical Therapy, Pediatric Physical Therapy

Sang Young Park: acaprio@hanmail.net

Highest degree: MS, Department of Physical Therapy, Daegu University Position title: Doctoral candidate, Department of Rehabilitation Science, Daegu University

Areas of interest: Biomechanics, Ergonomics, Neurological Physical Therapy
Date Received : 2010-07-26

Date Revised :2010-12-01

Date Accepted : 2010-12-02 